\title{
NCCN's Commitment to Medication Safety: The Vincristine Initiative
}

Jessica Sugalski, MPPA ; F. Marc Stewart, MD ; and Robert W. Carlson, MDa

\begin{abstract}
The mission of NCCN is to improve the quality, effectiveness, and efficiency of cancer care so that patients can live better lives. Improving medication safety is an important aspect of fulfilling this mission. In September 2014, the NCCN Best Practices Committee began a medication safety initiative to improve the safe use of vincristine. This article describes and discusses this initiative.
\end{abstract}

J Natl Compr Canc Netw 2016;14(8):959-960

The mission of NCCN is to improve the quality, effectiveness, and efficiency of cancer care so that patients can live better lives. Improving medication safety is an important aspect of fulfilling this mission. In 2006, NCCN conducted a patient safety summit where clinical leaders from NCCN Member Institutions discussed the most pressing patient safety issues facing cancer centers at that time. These leaders determined that NCCN should develop chemotherapy order templates to improve the safe use of drugs and biologics in cancer care. The first chemotherapy order templates were published in 2008, and today, NCCN has published more than 1,250 individual templates for 45 cancer sites, which are used by more than 10,000 subscribers.

NCCN continues to consider opportunities that will assist member institutions and other cancer treatment facilities in achieving the highest levels of medication safety for patients. In September 2014, the NCCN Best Practices Committee began a medication safety initiative to improve the safe use of vincristine.

Vincristine is administered intravenously most frequently for patients with leukemia or lymphoma. These patients may also require other chemotherapy agents that are sometimes administered intrathecally. Although rare, incidences have been described in which vincristine was

From a NCCN, Fort Washington, Pennsylvania, and 'Seattle Cancer Care Alliance, Seattle, Washington.

Submitted June 21, 2016; accepted for publication July 7, 2016.

Ms. Sugalski and Dr. Carlson are employees of NCCN. The authors

have disclosed that they have no financial interests, arrangements, or mistakenly injected into the cerebrospinal fluid (CSF) of patients when the intent was to inject another intrathecal chemotherapy agent, such as methotrexate or cytarabine. ${ }^{1}$ Vincristine given intrathecally is associated with an irreversible, painful ascending paralysis and is nearly always fatal. ${ }^{2}$ Even in extremely rare cases in which patients survived because such mistakes were recognized immediately, these patients are left with profound neurologic deficits. In fact, the Institute for Safe Medication Practices (ISMP) published safety alerts as early as 1998 and again in 2000 regarding this devastating error. ${ }^{3,4}$

This NCCN Best Practices Committee initiative was motivated in part by a patient story. One physician recalled treating a patient transferred from another institution after the accidental intrathecal administration of vincristine as part of lymphoma treatment. Over the next few days, the patient's family and medical staff witnessed a vibrant young man with a likely curable malignancy die because of a preventable medical error.

The NCCN Best Practices Committee determined that if vincristine was prepared for administration only via a flexible infusion bag (eg, $50 \mathrm{~mL}$ saline minibag) and never via a syringe, this would prevent the potential administration of vincristine intrathecally because it would ensure a mechanical barrier to intrathecal 
administration. Intrathecal chemotherapy is never administered via a flexible infusion bag; it is only administered by a slow push via a small-volume syringe. It is currently common at many institutions and infusion centers for vincristine to be prepared in a syringe, which provides no mechanical barrier to inadvertent intrathecal administration.

Proposals to eliminate the possibility of administering vincristine intrathecally by preparing it only in flexible infusion bags have also been recommended by other organizations, including the ISMP, Joint Commission, and WHO. ${ }^{1,5,6}$ Moreover, the ISMP included this proposal as a best practice in the organization's "Targeted Medication Safety Best Practices for Hospitals" publication in both the 2014-2015 and 2016-2017 issues. The NCCN Best Practices Committee set a goal to ensure that all NCCN Member Institutions would follow this recommended policy.

Accordingly, NCCN sent information outlining the recommended policy, the rationale for the policy, and relevant references to the Pharmacy \& Therapeutics Committees of all (then) 24 NCCN Member Institutions in October 2014; initial information indicated that 16 institutions had already adopted the policy. NCCN communicated frequently with pharmacy contacts at the other member institutions to remain updated on progress toward implementing the vincristine safety recommendations. Today, all $27 \mathrm{NCCN}$ Member Institutions follow the recommendation to prepare vincristine in flexible infusion bags only.
NCCN and the NCCN Best Practices Committee are proud of this achievement and thankful for the support and participation of the member institutions in reaching this goal. Further, our efforts will not stop here; NCCN's next step in this initiative is to challenge all medical centers, hospitals, and oncology practices nationwide to implement this medication safety policy to prevent even more fatalities. NCCN challenges all practitioners who treat cancer across the nation to follow the lead of the $27 \mathrm{NCCN}$ Member Institutions and help ensure this error never happens again.

\section{References}

1. Information Exchange System alert no. 115. Geneva, Switzerland: World Health Organization. Available at: http://www.who.int/patientsafety/ highlights/PS_alert_115_vincristine.pdf. Accessed July 14, 2016.

2. Burgess N. High-risk medication alert for vincristine injection. Appendix 3: literature review. Collingwood, Australia: Society of Hospital Pharmacists of Australia Federal Secretariat; 2005.

3. Institute for Safe Medication Practices. Accidental administration of IV meds intrathecally. ISMP Med Saf Alert 1998;3:1. Available at: http:// www.ismp.org/newsletters/acutecare/articles/19980923.asp. Accessed July $14,2016$.

4. Institute for Safe Medication Practices. Pain, paralysis, and knowledge of impending death marks intrathecal vincristine. ISMP Med Saf Alert 2000;5;1. Available at: http://www.ismp.org/newsletters/acutecare/ articles/20000405.asp. Accessed July 14, 2016.

5. Institute for Safe Medication Practices Canada. Published data supports dispensing vincristine in minibags as a system safeguard. ISMP Can Saf Bull 2001. Available at: http://www.ismp-canada.org/download/safetyBulletins/ ISMPCSB2001-10Vincristine.pdf. Accessed July 14, 2016.

6. Preventing vincristine administration errors. Sentinel Event Alert 2005;14:1-3. 